\title{
La tragedia griega en el teatro contemporáneo: un análisis de Incendios de Wajdi Mouawad
}

\author{
Q Rosa Anna Ferrando Mateu \\ Universitat Jaume I de Castelló \\ alo97391@uji.es
}

Fecha de recepción: 30/o8/2018. Fecha de aceptación: 26/10/2018.

\begin{abstract}
Resumen
El presente estudio se centra en el análisis de la literatura contemporánea cuya formalidad textual se forja, tanto estructural como, en cierto modo, temáticamente, a partir de los fundamentos elementales de la tragedia griega clásica. Para ello tomaremos el ejemplo de la obra del dramaturgo libanés Wajdi Mouawad, Incendios, donde entremezcla tintes autobiográficos con fuentes de la tragedia griega clásica, siendo más evidente la de Edipo Rey es decir, la relación entre la madre y el hijo y el descubrimiento de la Verdad, que ya aparece en la Poética de Aristóteles. También encontramos el caso de Cadmo y la búsqueda de un familiar raptado y la importancia del aprendizaje del lenguaje para entender los acontecimientos que suceden.
\end{abstract}

\section{The Greek Tragedy in Contemporary Theatre: an Analysis of Wajdi Mouawad's Incendies}

\begin{abstract}
The present study focuses on the analysis of contemporary literature which has a textual formality that is forged, both structurally and, in a sense, thematically, by the fundamental aspects of classical Greek tragedy. In order to do this, we would take the example of Incendies, the work of the Lebanese playwright Wajdi Mouawad, where autobiographical hints are interspersed with sources of classical Greek tragedy, the most evident of which is the one of Oedipus Rex; that is to say the relation between the mother and the son and the discovery of the Truth, which already appears in Aristotle's Poetics. We also find the case of Cadmo and the search for a kidnapped family member and the importance of learning the language so as to understand the events that take place.
\end{abstract}

Palabras clave

Mouawad Incendios Guerra Civil Libanesa tragedia griega

Keywords

Mouawad Incendies Lebanese Civil War Greek Tragedy 


\section{La obra y su autor}

Wajdi Mouawad, dramaturgo, director de escena y actor, nació en 1968, en Beirut donde transcurrió su infancia. Cuando tenía ocho años, en 1977, huyendo de la guerra civil que asoló el Líbano durante más de una década, se vio obligado a trasladarse junto a su familia a Francia. En 1983 tuvo que volver a buscar refugio en otro país, Canadá, estableciéndose finalmente en Quebec. Estudió y se graduó en 1991 en la Escuela Nacional de Teatro de Montreal, participando en varios grupos teatrales canadienses. Obtuvo, en 1998, el premio de la crítica de Quebec por su obra Willy Protagoras enfermé dans les toilettes [Willy Protágoras encerrado en los baños]. Más recientemente, en 2008, es nombrado director artístico del Teatro Francés del Centro Nacional de las Artes de Ottawa.

Wajdi Mouawad viajó, por primera vez desde su exilio, al Líbano, en 1992, en cuanto se firmaron los tratados de paz. Allí escuchó en primera persona los relatos de los supervivientes de la guerra, de los cuales, el autor toma prestadas parte de sus historias. Las referencias en la construcción del relato están vinculadas a la ocupación del sur del Líbano por Israel, las masacres de los campos de refugiados de Kfar Riad y Kafar Matra en 1978 y las de Sabra y Chatila en 1982, cuando el ejército israelí rodeó esos campos palestinos e ingresaron las falanges cristianas para masacrar a cerca de dos mil palestinos (Martínez, 2013: 45). La guerra en el Líbano, los conflictos fratricidas, la cuestión regional, la presencia de Siria, la ocupación israelí están presentes en todo el texto. Pero, poco a poco, el hecho histórico en la obra desaparece perdiendo su referencia, su identidad para dar paso a una visión universal con el fin de que el espectador pueda formar parte de ella y sentirse más cerca de la historia y llegar a concienciarse.

Aun siendo el teatro el género literario al que pertenecen la mayoría de sus obras, también se ha adentrado en el mundo de la novela, publicando en 2012 Ánima, ganadora en España del XV Premi Llibreter 2014. La obra teatral que centra este estudio, Incendios, forma parte de la tetralogía, La sangre de las promesas, iniciada con Litoral (1999), seguida de Incendios (2003), Bosques (2006) y, finalmente, Cielos (2009). En España, KRK Ediciones ha publicado dichas piezas, traducidas por Eladio de Pablo. De las cuatro obras que forman la tetralogía es precisamente en Incendios donde encontramos su pieza más realista en la que nos muestra el horror, la tragedia y el sinsentido de las guerras y la violencia en general. Así pues, en palabras de Anna Casassas,

el mal es omnipresente, tiene mil cabezas, como una hidra, mil cabezas y mil formas: guerra, violencia física, brutalidad, odio..., pero también la violencia del silencio, del abandono, del miedo. Un silencio que puede ser individual o puede ser colectivo, un silencio que nos aplasta, que anula la memoria y nos deja huérfano; el abandono de un hijo o el abandono de una promesa, de la promesa de no abandonar; y el miedo..., de saber ¿qué ha pasado antes de nosotros y qué llevamos como herencia? (2017: 461, traducido)

Este hecho, el de la reconstrucción de la historia para la formación y memoria colectiva, se muestra en este argumento como un acto tan necesario para las sociedades como la misma construcción del presente a partir de unos valores y unos conceptos identitarios determinados. Asimismo, tal y como afirma Ana Prieto en su artículo "Los cielos incandescentes de Wajdi Mouawad", el autor nos dirige la mirada "hacia el pasado donde se escenifica una pesquisa que nos llevará desde la ceguera y la ignorancia hasta la verdad y el reconocimiento del dolor colectivo, un remontarse a las generaciones anteriores para conocer la propia identidad y reconstruir la propia historia" $(2014,53)$. 
El denominado teatro contemporáneo ha ido evolucionado y, tal vez, por esa razón, podríamos situar la obra Incendios como la vuelta a la ideología del texto. El teatro vuelve a tratar temas ideológicos con el uso de un texto realista. En la obra podemos observar cómo no se describe un espacio concreto, un espacio cuyo vacío es una forma de reflejarnos más expresivamente la fuerza del texto (Paré, 2013: 44).

\section{Incendios: su argumento y tema}

En Incendios nos hallamos en el teatro del discurso, en el que el texto vuelve a ser centro del debate. Pep Paré nos dirá que "las escrituras dramáticas contemporáneas plantean una nueva inserción de las subjetividad, de la narratividad y del lirismo como procedimientos que recuperan el diálogo" (2013:42, traducido). Se investiga sobre el texto y, además, se experimenta sobre el espacio y las técnicas interpretativas. Esto lo observamos en el ejemplo de la compañía Schaubühne berlinesa y cómo, en 1999, con su nueva orientación se implica en un compromiso con los problemas sociales actuales, donde se habla de la tragedia humana cotidiana y la perspectiva capitalista del nuevo mundo (Paré, 2013: 43).

Incendios empieza en el despacho de un notario, Hermile Lebel, que lee el testamento de Nawal Marwan a sus hijos gemelos. En él da las instrucciones de cuáles van a ser sus últimas voluntades, entre ellas que su hija Jeanne entregue un sobre a un padre que creían muerto y que su hijo Simon, entregue otro a su hermano cuya existencia ignoraban. Éste puede ser el principio de la obra, ya que así empieza el texto, pero también podemos encontrar, más adelante, un nuevo principio, con una joven Nawal, de catorce años, enamorada, feliz y embarazada. Ése es el verdadero origen de la historia.

Mouawad nos propone regresar a nuestros orígenes, hacer una vuelta al pasado, a la propia identidad y recuperar lo que fuimos. Narrando la historia de una manera anónima, anacrónica y utópica nos propone una biografía posible para toda la humanidad. Todos podemos ser esos protagonistas y todas las guerras civiles tienen unas repercusiones casi idénticas en las sociedades que las sufren en primera persona y las mismas consecuencias para los ciudadanos que habitan ese espacio devastado. Aunque entendemos, por una serie de referencias que aparecen en el texto, que el país en el que se desarrolla la acción es el Líbano, Mouawad no lo nombra en su obra.

Nawal Marwan nace en una tierra en conflicto, donde encuentra el amor y la felicidad a los catorce años, pero pronto la guerra hará que su amado desaparezca y el hijo, fruto de esa relación, le sea arrebatado. La guerra convierte el amor en dolor. Y Nawal decidirá iniciar una búsqueda de ese hijo nacido del amor.

\section{La mitología en Incendios}

El género trágico está presente en casi todo el texto, en la medida en que la trama nos recuerda a la tragedia clásica con historias como la de Cadmo y la de Edipo. Se trata del castigo a las atrocidades cometidas por el género humano, tanto si nos referimos a Grecia clásica como al Líbano. La destrucción de Tebas representa la guerra del Líbano que obligó al autor a exiliarse.

En la mitología griega, Cadmo nació en la tierra de Canaán y tuvo que abandonar su país, Fenicia, en búsqueda de su hermana Europa, raptada en las playas de Tiro por Zeus. Después de una infructuosa búsqueda, fundó una ciudad que posteriormente se conocería como Tebas, convirtiéndose en un maestro que enseñó el alfabeto a los griegos. 
Como hemos dicho, en Incendios, la protagonista también abandona su hogar en búsqueda de su hijo arrebatado, nada más nacer, de sus brazos. Y en esa búsqueda, también infructuosa, es donde ella aprenderá a leer, cumpliendo de ese modo la promesa que le hizo a Nazira, su abuela, en el lecho de muerte. Así Nazira le aconsejará que para poder rebelarse, era conveniente saber hablar. "Aprende a leer, aprende a escribir, aprende a contar, aprende a hablar. Aprende. Es tu única posibilidad de no parecerte a nosotros" (Mouawad, 2011:83).

El teatro de Mouawad es un teatro de la palabra y, como dice Ricardo Menéndez, "hace de esta plataforma condena y furia, desgarro y voluntad de aprehender el flujo desordenado de lo que sucede, una respuesta radical por el lenguaje como depósito de la emoción, pero también de la inteligencia que la fecunda y, tantas veces, destruye" (2014: 98).

Edipo, Antígona, Macbeth, entre otros, son personajes con un destino escrito, aunque son ellos quienes no cejarán hasta conocer la verdad. El Edipo de Sófocles es el héroe trágico por excelencia, que no se detendrá hasta saber quién es en realidad y cuáles son sus orígenes, aunque siente que cada vez que se encuentra más cerca de esa verdad, más próximo se sitúa al horror del desenlace. Como el rey de Tebas, hijo de Layo y Yocasta, quien, sin saberlo, mató a su propio padre y se desposó con su madre, así, a través de esta búsqueda, consigue reconocer las relaciones entre el deseo, el saber y la ignorancia.

El descubrimiento por parte de los personajes, el caso de Edipo o el de Nawal, de su identidad, de sus orígenes o de su entorno que hasta entonces le estaban ocultos, es un momento de anagnórisis, ya que a los protagonistas le es revelada la verdad con unos efectos casi demoledores.

Con el tono de la tragedia griega, Nawal como Yocasta encontrará a Edipo, continuando el desarrollo de la historia de manera diferente a la tragedia griega. Nawal buscaba a su hijo y, una vez que lo encuentra, no lo reconoce. Nihad, el hijo arrebatado de los brazos de su madre, dado en adopción y educado para ser miliciano en la guerra, buscaba a su madre y, una vez delante de ella, tampoco la reconoce. El hijo torturó y violó a su madre. Aunque la historia puede ser una historia de todos los tiempos, en realidad, es una historia del ahora. Jeanne y Simon son hijos nacidos del horror pero Nawal se niega a reconocer que ese sea el origen de su historia, pues ella quiere que el origen se encuentre en ese hijo nacido del amor cuando ella era joven.

\section{Los personajes y su significación}

Sawda es la joven a quien Nawal enseña a leer y a escribir mientras transcurre la búsqueda de su hijo. Entre estos dos personajes se mantienen las conversaciones más complejas de la historia, las que más aclaran las situaciones en una guerra civil fratricida, que son las que en realidad duelen. De este modo Sawda preguntará: “¿Entonces qué hacemos? ¿Qué hacemos? ¿Quedarnos con los brazos cruzados! ¿Esperamos? ¿Comprendemos? ¿Comprendemos qué? ¡Palabras! ¡De qué sirven las palabras, dime, si yo hoy no sé lo que debo hacer! ¿Qué hacemos, Nawal?" (Mouawad, 2011: 141). Hay que buscar cómo acabar con los conflictos sin entrar en la dinámica de aumentarlos, evitando el ojo por ojo y la venganza en lugar de la justicia.

Nawal y Sawda son dos personajes que se rebelan contra el destino por haber nacido en una tierra y en una historia, en un espacio y en un tiempo. Paradójicamente, aunque es Sawda la primera que quiere la violencia para acabar con la violencia, al final será Nawal la que la lleve a la práctica, teniendo conciencia de sus actos. La obra 
se vuelve una auténtica tragedia griega al recordarnos ese destino marcado desde el momento en que nacemos, el que, pese a que intentemos evitarlo e ignorarlo, nos alcanzará de lleno. El destino aparece, por tanto, como un elemento inevitable y trascendental, un elemento desconocido contra el que no podemos actuar y del que depende, en definitiva, la experiencia vital de cada individuo con independencia de su clase social, sexo, género, raza e incluso espacio temporal y geográfico en el que se habita.

La joven Jeanne, hija de Nawal, profesora de matemática teórica en la Universidad de Quebec, cree encontrar en esa disciplina las repuestas a todas las preguntas. Ella vive aislada en un mundo ideal, lejos de su lugar de origen, donde todos los problemas tienen solución, pero llega un momento en el que aparece una variable en la ecuación que hace que la solución a ese problema no sea la que nos esperábamos. Y cuando Simon le pregunta "Siempre me has dicho que uno y uno suman dos. ¿Es eso verdad? [...] ¿Uno y uno pueden sumar uno?” (Mouawad, 2011: 184), Jeanne tiene que reconocer que sí. Las matemáticas reflejan el lado racional del ser humano; por lo que las abandona, para dejar paso a los sentimientos. De esta forma, Jeanne observa cómo la justificación vital, en la que trata de explicar su propia existencia, se desmorona y observará cómo la propia lógica de las matemáticas también es una construcción creada por el propio ser humano. El constructivismo filosófico aparece en este apartado como elemento en el que observamos cómo las propias cuestiones, sobre las que intentan basar la vida, son también construcciones hechas a la medida de lo humano.

En la historia, Nawal tiene indistintamente catorce, cuarenta y cinco y sesenta años. En ocasiones, nos encontramos a los personajes de Nawal de diferentes edades compartiendo escena, o cómo Nawal, de cuarenta y cinco años, habla a su hija Jeanne. La interacción de diferentes líneas de tiempo en un mismo espacio es también un reflejo de su paso inexorable, de la mutabilidad de los elementos y del cambio constante al que nos enfrentamos como individuos. El mundo es cambiante, como las personas y, precisamente, la intersección de diferentes tiempos en un mismo espacio nos muestra los cambios que se pueden experimentar, en primera persona o, de forma dialéctica, entre distintos personajes que interactúan.

La forma en que se encuentran en escena los personajes y el tema de la matemática nos hace recordar El chico de la última fila del dramaturgo madrileño, Juan Mayorga, donde los personajes comparten escenario y situaciones, aunque no pertenecen al mismo espacio y tiempo. En esta obra, la matemática también tiene su importancia, ya que, gracias a ella, el protagonista puede entrar en la casa a dar clases de refuerzo a su compañero y, de este modo, formar parte de una nueva familia.

\section{Puesta en escena y la adaptación cinematográfica}

Incendios ha sido representada en diferentes ocasiones en España. En septiembre del 2016 ha sido llevada a escena en el Teatro de la Abadía en Madrid, bajo la dirección de Mario Gas, con la actuación de Nuria Espert en el papel protagonista de Nawal. En este montaje se suceden las escenas sin interrupciones y pasado y presente conviven de manera simultánea. Aún así, es un formato más clásico, ya que la distribución del espacio de representación sigue las pautas tradicionales. Más arriesgada fue la puesta en escena por la compañía La perla 29 en el teatro la Biblioteca de Catalunya, en junio del 2015, con dirección de Oriol Broggi, donde el público se encontraba rodeando el espacio escénico y se conseguía la participación de los espectadores. La oportunidad que les daba el espacio del teatro de la Biblioteca de eliminar el escenario, hizo que los límites entre el público y la representación se diluyeran. 
También ha sido adaptada al cine en el año 2010, por el director canadiense Denis Villeneuve. En la película, se pueden observar algunos cambios importantes, aunque es posible que fueran necesarios para su adaptación cinematográfica. Entre ellos, que los protagonistas tienen nacionalidad, lugar y nombre. Nawal es una cristiana libanesa exiliada en Canadá, que se enamoró de un palestino musulmán. Ahora nos podemos situar en un espacio y tiempo concretos y, de esta manera, la universalidad que conseguía la obra de teatro se pierde. Otras ausencias que podemos observar son la pérdida de la importancia de la matemática, la desaparición del personaje de Sawda, su compañera, y los silencios de Nawal que ésta graba en casetes. En el texto teatral, la palabra se revela a veces insuficiente, incapaz de describir el horror y el dolor demasiado pesado para ser dicho; por ese motivo Nawal Marwan decidirá pasar en silencio sus últimos años. El tema principal de la película es la destrucción y la muerte que van descubriendo mientras realizan la búsqueda del padre. Es curioso cómo en la película las imágenes toman más protagonismo quitándoselo a las palabras. Aún así, es una excelente adaptación, muy fiel a la obra de teatro.

\section{Conclusión}

Para finalizar, podemos afirmar que la obra Incendios sigue el mismo esquema que la tragedia griega, donde sus personajes, aún negándose en un principio a averiguar la verdad, llegarán a descubrirla. Jeanne desde el comienzo quiere descubrir el origen de su historia; su hermano Simon, en un principio quiere olvidar su pasado, pero más tarde se unirá a su hermana en la búsqueda de esa verdad. Nihad, el padre y hermano, al final de la obra descubrirá quién es en realidad y cuáles fueron sus actos y sus consecuencias. Todos ellos vivían en la ceguera y en la ignorancia hasta que descubren la verdad y, con ella, el reconocimiento del dolor. Sin duda, una llamada que nos indica que debemos saber la verdad por dura que sea ésta y su mensaje. Y, una vez descubierta, será recibida como una catarsis, como una liberación o transformación interior.

En la obra, tanto el habla como el silencio son elementos que adquieren destacada significación. Nawal promete a Nazira que adquirirá las herramientas para aprender a leer, escribir y pensar. Y más tarde, enseñará a Sawda a utilizar los elementos del lenguaje como nuevas armas para solucionar los conflictos. En Incendios, también aparece la canción, que se utiliza como desafío a la fuerza militar dominante y se presenta como modo de consuelo, frente a una realidad cuya capacidad de ser cambiada no siempre recae en nosotros mismos.

Después de una guerra y de esos hijos nacidos del horror se silenciará la verdad, aunque Nawal, en lugar del autor, nos afirmará que donde hay amor no puede existir odio y que para preservar el amor, ella eligió callarse. Pero ha llegado el momento de reconstruir esta historia destrozada. Por debajo de todas las identidades subsiste la vinculada a la filiación. La fragilidad de la identidad es una demostración de la incertidumbre de la memoria o de la duda de su autenticidad.

La búsqueda de la historia y de la identidad está presente en toda la tetralogía de Mouawad, La sangre de las promesas. Y esta obra, Incendios, es un fiel reflejo de esta característica del autor, ya que finalmente, gracias a la ayuda de sus hijos y el desarrollo de ese viaje a través de su propia búsqueda, la protagonista logra recuperar y restaurar su identidad. 


\section{Q Bibliografía}

"Casassas Figueras, A. (2017). "Postfaci. El bou escorxat”. En Mouawad M., La sang de les promeses. Barcelona: Edicions del Periscopi.

" Graves, R. (2004). Los mitos griegos. Barcelona: Círculo de Lectores.

»Lebel, J. (1967). El happening. Buenos Aires (Argentina): Ediciones Nuevas Visiones.

" Martínez Assad, C. (2013). “Wajdi Mouawad. Sobrevivir en el infierno”. Revista de la Universidad de México, 41-45.

" Menéndez Salmón, R. (2014). “Wajdi Mouawad o la sangre de las promesas". Quimera $n^{\circ}$ 361. Revista de Literatura, 98.

» Mouawad, W. (2011). Incendios. Oviedo: KRK Ediciones.

"Mouawad, W. (2017). La sang de les promeses. Barcelona: Edicions del Periscopi.

»Paré, P. (2013). “Teatre contemporani, panoràmica a vol d'ocell”. En Arts escèniques, Barcelona: UOC.

"Prieto Nadal, A. (2014). "Los cielos incandescentes de Wajdi Mouawad". Quimera $n^{\circ}$ 372. Revista de Literatura, 53-55.

"Teatro Abadía documentos, “Incendios-dossier”, Teatro de La Abadía, [en línea]. Consultado el 20 de octubre de 2017 en http://www.teatroabadia.com/en/ uploads/documentos/incendios-dossier.pdf

» Teatro.es Catálogo, “Incendis. Wajdi Mouawad. La Perla 29”, Centro de Documentación Teatral, [en línea]. Consultado el 20 de octubre de 2017 en <http:// teatro.es/++resource++portalcdt.theme.images/multimedia/doccom/ esp/44515_2.pdf_pdf.pdf >

» Telmissany, M. (2012). "Wajdi Mouawad in Cinema. Origins, Wars and Fate". Cine action (88), 48-57, [en línea]. Consultado el 20 de octubre de 2017 en http:// www.academia.edu/7346040/Wajdi_Mouawad_in_Cinema_Origins_Wars_ and_Fate 